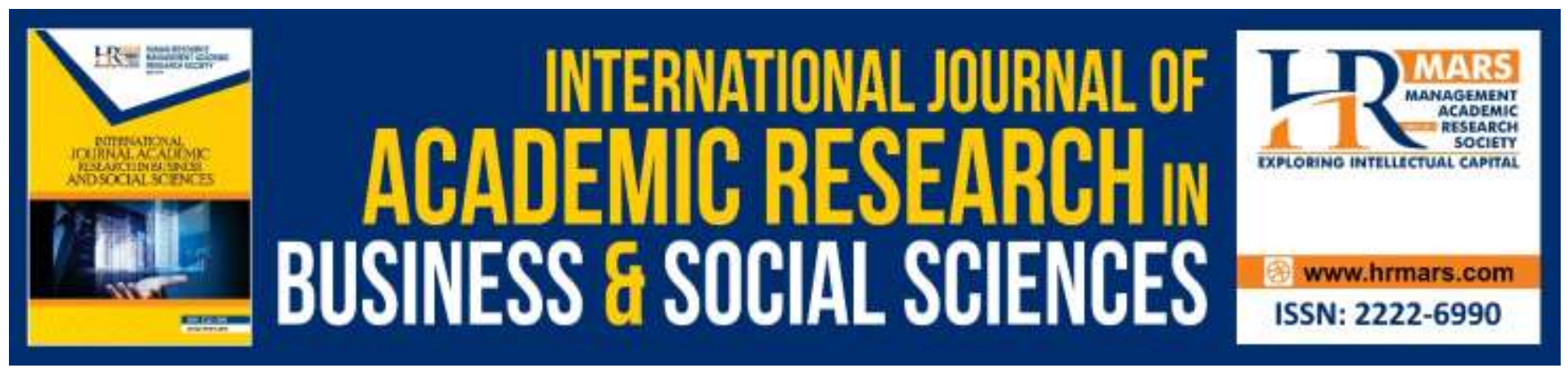

\title{
Anchoring and Adjustment Bias in Working Capital Management and Performance of Small and Medium Enterprises (SMEs): The perspectives of Ghanaian SMEs Managers
}

Jeff Lamptey, Asri Bin Marsidi

To Link this Article: http://dx.doi.org/10.6007/IJARBSS/v10-i5/7181

DOI:10.6007/IJARBSS/v10-i5/7181

Received: 02 March 2020, Revised: 08 April 2020, Accepted: 23 April 2020

Published Online: 06 May 2020

In-Text Citation: (Lamptey \& Marsidi, 2020)

To Cite this Article: Lamptey, J., \& Marsidi, A. Bin. (2020). Anchoring and Adjustment Bias in Working Capital Management and Performance of Small and Medium Enterprises (SMEs): The perspectives of Ghanaian SMEs Managers. International Journal of Academic Research in Business and Social Sciences, 10(5), 143-156.

Copyright: (C) 2020 The Author(s)

Published by Human Resource Management Academic Research Society (www.hrmars.com)

This article is published under the Creative Commons Attribution (CC BY 4.0) license. Anyone may reproduce, distribute, translate and create derivative works of this article (for both commercial and non-commercial purposes), subject to full attribution to the original publication and authors. The full terms of this license may be seen

at: http://creativecommons.org/licences/by/4.0/legalcode

Vol. 10, No. 5, 2020, Pg. 143 - 156

http://hrmars.com/index.php/pages/detail/IJARBSS

JOURNAL HOMEPAGE

Full Terms \& Conditions of access and use can be found at http://hrmars.com/index.php/pages/detail/publication-ethics 


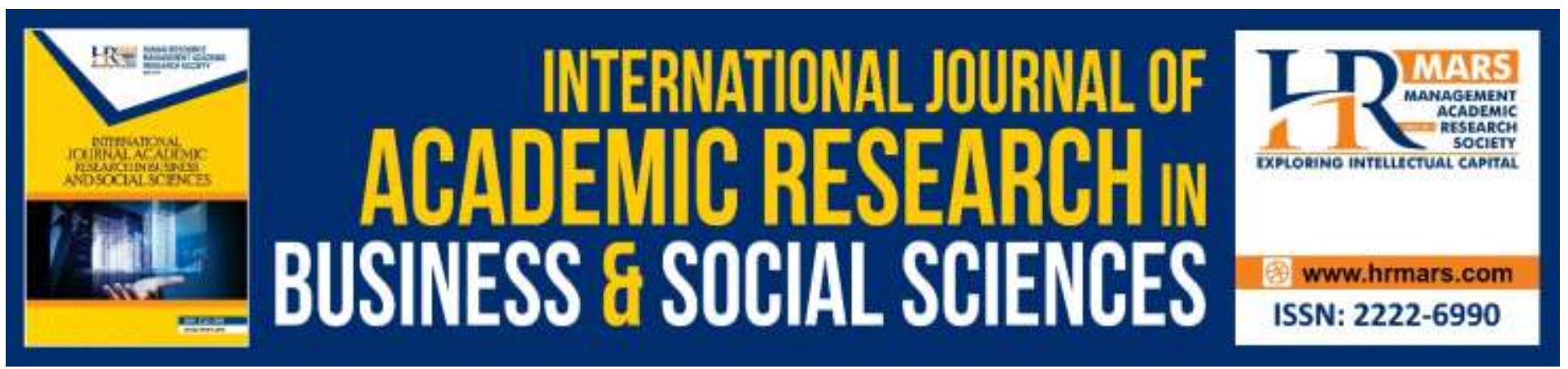

\title{
Anchoring and Adjustment Bias in Working Capital Management and Performance of Small and Medium Enterprises (SMEs): The perspectives of Ghanaian SMEs Managers
}

\author{
Jeff Lamptey, Asri Bin Marsidi \\ Faculty of Economics and Business, Universiti of Malaysia Sarawak \\ Email: jefflampt@gmail.com maasri@unimas.my
}

\begin{abstract}
This paper explored Anchoring and Adjustment in working capital management and performance of small and medium-sized enterprises (SMEs) in Accra, Ghana. We adopted a qualitative case study design and employed in-depth interviews to obtain data from thirty-five (35) managers drawn from trading manufacturing sectors. We found that SME managers(owners) primarily rely on selfgenerated and provided anchor. More specifically, managers anchor on customer's trust, price list and quotation, current and past sales trends which results to overinvestment and underinvestment in working capital and higher or lower performance. Therefore, we conclude that anchoring and adjustment in working capital management and performance matter.
\end{abstract}

Keywords: Anchoring and Adjustment, Working Capital Management, Performance, SMEs Managers, Ghana.

\section{Introduction}

Managerial bias and particularly anchoring and adjustment appears to influence economic decision under uncertainty. When people face complex economic decision problem requiring substantial time and cognitive ability, they have difficulty in following rational approach developed for analysing and selecting optimal choice, but rather adopt more subjective method of reasoning to determine appropriate course of action consistent with their desired preference and outcomes(Pompian, 2012; Maharani, \& Witiastuti, 2015) In the course of making estimate or judgement, they usually start with initial value which is adjusted to attain the desired estimate. The initial value, which is the anchor can be suggested or personally computed based on the nature of the problem. In each case, adjustment is insufficient because different initial values lead to different final estimates (Tversky and Kahneman, 1974). It has been reported that anchoring and adjustment influence many intuition decisions. However, there is a growing concern that influence of anchoring and adjustment is lagged in working capital management many years. And as of today, literature in 
anchoring and adjustment in this field of research is limited. As majority of the studies on anchoring in economic decision pertain to individual investors (Baker et al. 2012; Duclos, 2015) and fund managers (Hirshleifer, 2001; Park, 2010). However, is there are so far limited knowledge about anchoring and adjustment bias of SME managers in working capital management and performance which remains a key financial decision of SMEs. Although, SMEs managers are required to follow standard working capital management practices for optimal solution, but rather employ subjective approach to working capital decision: cash, inventory, receivables and payables to maximize performance (Filbeck and Lee, 2000; Bandara and Rathnasiri, 2016). By so doing, managers rely on their experience as a useful framework for working capital investment and financing decision to achieve desire profit. As a result, managers rely on of rules of thumps in inventory decisions (Kamilah Ahmad et al. 2014). Yet, we still have not incorporated SMEs managers' anchoring and adjustment bias into working capital management and performance literature. Thus, there is a need to strengthen the SMEs industry considering its impact on the economy and society, particularly in developing nations (Marsidi, 2019).

In Ghana, SMEs face a lot of uncertainty in working capital management decision and the lack of working capital practices compel managers to rely on their experiences to make cash, inventory and accounts payables decision (Hamza et al. 2015; Donkor,2015). But what informs managers working capital management decision to realise expected profits is subject to personal perspectives. We assumed that managers personal interest and preference might be key factors considering SMEs are noted for quick decisions. Making quick decision suggest that managers rely on some rules of thumb or shortcuts consistent with their preferences and interests just like other SME managers do (Madhoun and Al-Analoui ,2003 Gockel \& Akoena, 2002; Pansiri and Temtime, 2008) to maximize opportunity and enhance personal wellbeing. Thus in this article, our purpose is

- To explore anchoring and adjustment behavioral biases of SME managers

- To examine influence of anchoring and adjustment behavioral biases of SMEs managers working capital management and performance

\section{Literature Review}

\section{Anchoring and Adjustment Behavioral Bias}

One strategy people adopt in making decision under uncertainty is to rely on the information that come their mind, visualize or sighted a moment ago and adjust upward or downwards until preferred decision is reached (Epley and Gilovich, 2006). This approach exposes individuals to anchoring and adjustment bias which is found to influence many intuitive decisions due insufficient adjustment (Tversky \& Kahneman, 1974; Strack and Mussweiler, 1997). Initial studies on anchoring and adjustment commenced with experiment in which subjects first compare the target value with the initial value (anchor) and then ascertained final estimate or judgement. In the study, subjects were told to determine the number of African countries that belong to United Nations. The participants were asked first to state whether the percentage of the countries were higher or lower than a randomly provided number of countries and then gave their own estimate. The final estimate (i.e. African countries) were highly induced by the random value: high estimates were associated with high random number while low estimates were associated with low random numbers (Tversky and Kahneman, 1974).

In the real world, and in most economic decisions, Individuals under anchoring bias often rely both personal judgement or information or externally provided piece of information or value (Tversky 
and Kahneman, 1974; Hogarth, 1981). Early study found that the corporate executives anchor on a particular level of earning per share(EPS) in order to exceed the benchmark (Degeorge et al. 1999). Subsequently studies, for instance, George and Hwang (2004) noted that when individual investors anchor on historical highest prices, they do not sufficiently adjust stock price high as expected when the shares are close to their "peak historical prices". Additionally, Cen, Hilary, and Wei (2013) find that historical average stock price serves as anchor while investors estimate performance of listed companies Shanghai stock market.

Moreover, anchoring and adjustment have been found influential in real estate market and better market. The premium place on initial dollar value by bettors determine amount to wager on horse (Jetter and Walker, 2016). Furthermore, the priority bettors give to horse previous race position induce their decision (Johnson and Bruce, 2001). Thus the better the horse barrier position, the higher the anchor, the more likely bettors increase their bet. In addition, bettors consider expert advice, and information on movements in the bookmaker odds as important anchor to determine amount to bet on horses (Jones et al. 2004). However, the bettors used different procedures to choose the horse on which to wager. Additional evidence for anchoring and adjustment shows in the real estate market, buyer and home owners consider first offer (initial prices) as important anchor to market value (Northcraft and Neale, 1987).

Indeed, anchoring and adjustment effects have also been documented in several studies including judicial sentencing decisions (Englich, Mussweiler and Strack, 2006) job performance evaluation (Latham et al. 2008), sales predictions (Hogarth, 1981) negotiation outcomes (Ritov, 1996), Overall, anchoring plays a substantial role in financial decision-making under pressure or uncertainty.

\section{Anchoring and Adjustment Theory}

Anchoring and adjustment bias are a well- known mental shortcuts or cognitive heuristics arising from tendency to rely on some initial information or value to estimate by gradually adjusting it to arrive that final outcome (Tversky and Kahneman, 1974). Individuals anchoring and adjustment bias potentially stem from two sources: personally, computed or externally offered based on the nature of the decision. For example, individual investors have used several anchors such as historical stock prices, current prices closings and charts and previous month data and current market price estimating firm performance on financial; Campbell and Sharpe, 2009; Baker et al. 2012; Khan et al, 2017). Also, previous foreign ownership is considered as anchor to estimate "Foreign Institutional Investment", influencing momentum of foreign investments (Liao et al, 2013).

Meanwhile, investors in real market and betting market rely on initial price list (first offer) and barrier position to estimate market value of estate and bet. Other bettors have relied on movement in the bookmaker's odds to decide amount (Northcraft and Neale, 1987 Jetter and Walker, 2016).

Regardless of type of anchor used, the adjustment is usually insufficient because individuals have difficulties to integrate or quickly adjust new information, facts and figures into their cognitive process because they anchored on or hold firmly onto their existing views, particularly if the new information tends to contradict their earlier beliefs, views and others (Tversky and Kahneman, 1974; Epley and Gilovich, 2006). However, the implication of anchoring and adjustment in working capital management and performance is unknown Thus, we worthy to explore how anchoring bias of SME managers influence working capital and performance. 


\section{Methodology and Research Design}

We used qualitative research methods to gain in depth understanding of the nature of anchoring behaviors of SME managers. We reviewed anchoring bias as the key phenomenon being investigated requiring understanding because limited of knowledge (Domegan and Fleming, 2007; Birkinshaw et al. 2011; 575). Due to the nature of anchoring bias, we adhered to Strauss and Corbin (1998; 11) suggestions that "qualitative methods can be used to obtain the intricate details about phenomena such as feelings, thought, processes, and emotions that are difficult to extract or learn about through more conventional methods".

In terms of research method, we adopted single case as described by these scholars (Yin, 1994; Stake, 2000) as a study that involves one particular phenomena (e.g. a thing, process, event) or as one group (Yin, 2003). This method postulates that a single case study can lead to "develop indepth description and analysis of cases" (Siggelkow, 2007; Dyer and Wilkins, 1991; Creswell, 2018) and also create "better theory" (Dyer and Wilkins, 1991). Dyer and Wilkins further argue that "single case studies are better than multiple cases in terms of details and theorizing". Because, it allows the researcher to question existing theoretical relationship and establish new ones that requires in-depth exploration of phenomenon.

\section{Target Participants and Sample Selection}

Our target participants for this research are managers(owners) of small and medium sized enterprises(SMEs) based in Accra. We chose these managers mainly because of purpose of study (Cresswell et al. 2018). Purposive sampling method and snow balling method were considered over others non-probability sampling because of the nature of phenomena and research question requiring diverse perspectives.

Participants were recruited based on availability, readiness and willing to participate, ability to communicate in English language and local dialects, and above all "ability to articulate communicate experiences and opinions (Spradley, 1979 cited in Etikan, et al. 2016; 2). We expected that these sampling techniques provided us the opportunity to obtain the needed diverse information required from participants. The initial recruitment process begun after faculty approval of the research. At this stage fifteen (15) participants were reached through telephone whom through their help we contacted their peers. Tentatively, fifty-five (55) participants from the trading and manufacturing sectors in operating Central Business Centre (CBC), Greater Accra obliged to participate in the study. In the second phase of recruitment, only 45 participants met the requisite criteria (e.g., three years of managerial experience in working capital management and above 25 years of aged were selected) and explanatory letters and consent forms were emailed them for confirmation, and only 40 participants responded. Later some participants declined participation in the study for personal reasons. Our final participants made up of thirty -five (35) managers, men (20) and women (15) drawn from Trading sector (23) and manufacturing (12) with varied demographic characteristic as shown in Table 1 
Table 1: Social demographic of Participants

\begin{tabular}{ll}
\hline Participant & Number \\
\hline Age & 08 \\
$25-40$ & 20 \\
$41-50$ & 05 \\
$51-60$ & 02 \\
$61-$ and above & \\
Gender & 20 \\
Male & 15 \\
Female & \\
Education & 06 \\
Secondary & 05 \\
Diploma & 12 \\
Graduate & 08 \\
Professional & 07 \\
Master & \\
Managerial Experience(years) & 05 \\
$3-5$ & 09 \\
$6-10$ & 13 \\
$11-15$ & 06 \\
$16-20$ & 02 \\
21 and above & \\
Industry & \\
Trading & 12 \\
Manufacturing & 23 \\
\hline
\end{tabular}

\section{Data Collection and Instrument}

Data were obtained through semi structured interviews, which has been described by (Fontana and Frey, 2000; 645) as "one of the most powerful way in which we try to understand our fellow human being". Telephone interview was used because it is a valid means of collecting qualitative data (Cachia and Millward,2011; Glogowska et al. 2011, Trier-Bieniek, 2012; Vogl, 2013). As it offers a great deal of convenience just like face to face- to- face interviews (Deakin and Wakefield, 2014). However, Cachia and Millard (2011) argue that telephone interviews provide maximum privacy and comfort to participants to engage in lengthy conversation. In addition, it also offers the researcher opportunity to reach participants who hardly can be contacted personally due to business commitments (Fenig et al. 1993). Overall, these flexibilities stimulate the interest of participants and motivate interviewees to participate actively in the interviews (Cachia and Millward, 2011). 
INTERNATIONAL JOURNAL OF ACADEMIC RESEARCH IN BUSINESS AND SOCIAL SCIENCES

Vol. 10, No. 5, May, 2020, E-ISSN: 2222-6990 @ 2020 HRMARS

The interviews focused on anchoring and adjustment behaviors in working capital management and performance guided by interview protocols. The use of in-depth interview helped us capture actual behaviors of managers through opening ended conversion styles, probing, elaboration, clarification, reminders and quick recap (Shelden et al.2010; Burke and Miller, 2001; Glogowska et al. 2011). On average, each interview lasted between 60 to 180 minutes. Interviews were recorded, transcribed and then analyzed. Interview transcript and summary results were emailed to the participants for validation of the accuracy of their responses and positive feedbacks were received.

\section{Data Analysis}

The data analysis begun by identifying segment or patterns, that is, unit of data which is a potential finding or part of the answer to the research questions. Merriam (2009) explained that the unit of data can be any meaningfully a word or group or words used by the participants(managers) describe their feelings, behavior or occurrence. To identify these patterns in analyzing the data, we used thematic analysis which enabled the us to identify loss aversion behaviors of SMEs Managers and their influence working capital management and performance decision.

In search for main categories or themes, the interview transcripts were thoroughly read to familiarise with and make sense out of the data which ensured that participants responses on loss aversion behavior and influence on working capital management performance have been properly captured, transcribed and understood meanings of the data.

Next, the data were coded by making notes and comments that were potentially relevant to the research questions (Merriam, 2009). We used theoretical coding process which helped us to address specific research and each segment of data that was relevant was coded that capture exact word of participants, concept from literature or researcher own construct. This was done because we did have preset codes and the open coding process was used to search initial codes. All codes were entered into NVIVO software version 12 pro.

In order to stay focused on loss aversion behaviors, we then adjusted or reviewed and modified the initial individual theme identified into final themes being anchoring and adjustment behavior and their impact on working capital management and performance. The final themes are the main findings which gives more clarity on the descriptive accounts of SMEs managers behaviors in working capital and performance in our concept development map in Figure 1.

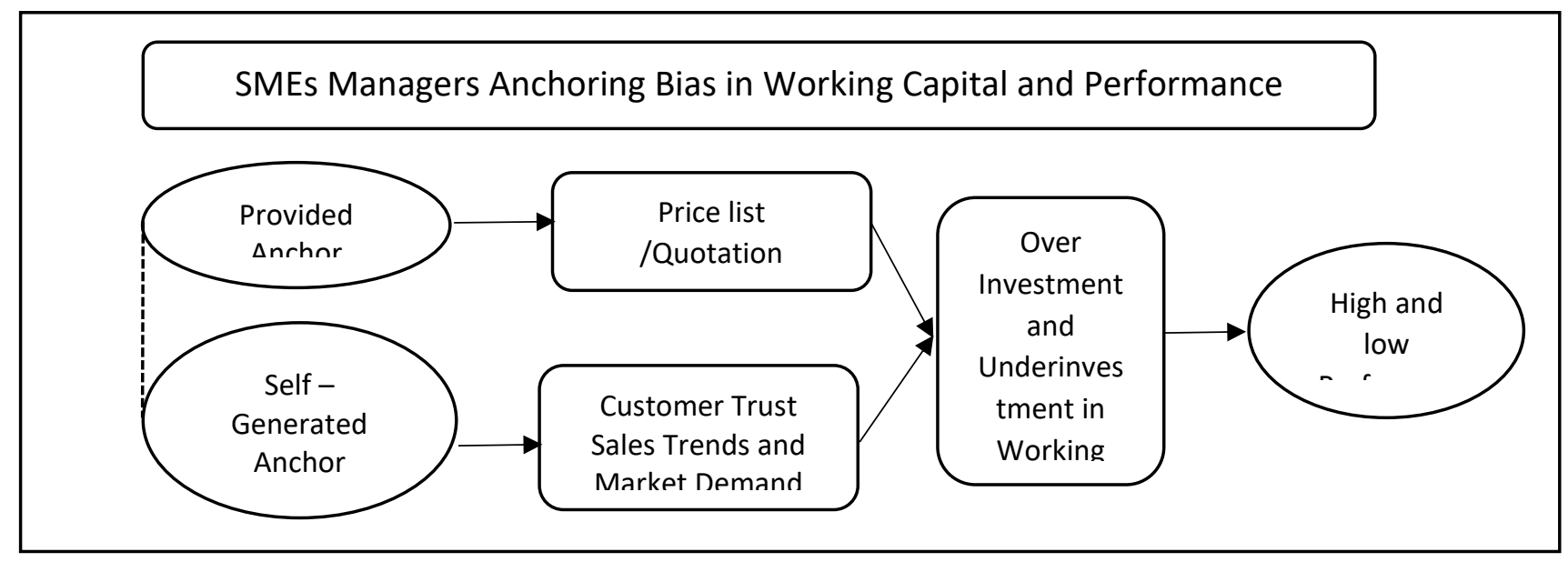


INTERNATIONAL JOURNAL OF ACADEMIC RESEARCH IN BUSINESS AND SOCIAL SCIENCES Vol. 10, No. 5, May, 2020, E-ISSN: 2222-6990 @ 2020 HRMARS

Figure 2: Mapping of findings of Anchoring and adjustment in working capital and performance

\section{Confirmability of Findings}

We confirmed our findings through member checks (Lincoln \& Guba, 1985; Creswell, 2003) and respondent validation (Bloor, 1978; Lincoln and Guba, 1985). To obtain respondents validation, the interview transcripts were presented to managers to through email or contacted them by telephone to check for accuracy of data, and emergent themes, that is, if they saw their personal responses reflected in any or all the transcripts. With member checks, managers were asked to express their opinion on the correctness of "verbatim quotes" and sought their consent to used them in our reports. All 35 participants confirmed that the findings and direct quotes adequately and accurately represented their views.

\section{Results and Discussion}

\section{Anchoring and Adjustment Behavioral Bias of SME Managers}

The interviews centered on anchoring bias and their influence on working management capital and performance decision. We found that participants exhibited anchoring bias because they depend largely on some known initial value or information to make decision. This finding emerged from two primary categories: self-generated anchor and provided anchor and their influence on working capital and performance resulted in overinvestment and underinvestment resulting in high or low performance. In addition, within main categories, we identified two subcategories which further explain SME manager's anchoring bias.

Provided anchors serves as initial or first offers for SMEs managers for making financial decision. Participants used either price list or quotations or both while making working capital inventory decision to determine the actual price of goods or stock and quantity to buy. The initial offers provide managers important information needed which tend be more convenient, ease inventory decision and estimation of cost or actual price of goods or stock and quantity to buy. For example, participant 12 stated that:

"I usually request price list from suppliers whenever I want to buy goods. This helps me to know the market value to decide the quantity to buy. I have not tried any other sources except this since it contains information I need and I am okay with this because I hardly struggle in estimating the cost of goods". Similarly, participant 10, considers pricelist as a key source for determining the market price of goods and stated that:" I have used this many times because it contains vital information that helps me decide amount of raw materials or stock to buy". It is a very simple way to ascertain prices of goods". However, several participants, included participants 5, used both price list and price quotation to make orders. This manager opined that: "I always request for price list or quotation from my suppliers to know the market prices first. This helps me know quantity of goods to buy and how much I will pay. Well, it convenient and facilitates my decision".

These comments show how participants value initial offers in determining market price of stock or inventory.

Self-generated anchor was another significant evidence of SME managers anchoring bias. We observed participants relied on market trend or market demand and customers trust. The market 
INTERNATIONAL JOURNAL OF ACADEMIC RESEARCH IN BUSINESS AND SOCIAL SCIENCES

Vol. 10, No. 5, May, 2020, E-ISSN: 2222-6990 @ 2020 HRMARS

trends stemmed from past sales and current sales which enabled managers estimate quantity of goods and expected sales revenue.

Based on this finding, participant 7 informed us that: "Relying on past and current sales have personally helped me(manager) to plan purchases and sales. I am able to meet, in most cases customer demands". Likewise, participant 10 also stated that: "The use of both current and past sales to make purchase and expected sales decision has been helpful. I can plan my quantity of goods to buy and expected sales periodically to meet customer's needs."

Customer trust was a key anchor for participants. This finding shows that managers trust for customers develop from existing healthy business relationship. Thus, customers trust is significant determinant of credit decision and customers' ability to pay credit. A case in point is participant 3, who stated that,

"I consider trust as key factor in granting credit to customers whom I have good business relationship with. This normally gives me some rough idea about their payment because they have been buying from me". Moreover, Participants 4 viewed trust as the most important factor in business and said that: "I will sell to regular customers on credit, especially those who have been buying from me over a period of time, since this will help me know if they can pay or not".

These findings suggest that participants value shortcuts to simplify complex decision making process. Thus, it can be assumed that SMEs managers(owners) have the requisite ability and experience to identify appropriate anchors suitable for specific decision. Therefore, the premium managers placed on the anchor largely influences outcome of the decision.

\section{The Influence of Anchoring and Adjustment Behavior on Working Capital Management and Performance}

SMEs managers anchoring bias resulted in overinvestment and underinvestment in working capital which increase and decreases performance.

Overinvestment in working capital is induced by low anchoring bias (low initial price offer). This anchor allows managers to invest substantially in working capital in inventory because the actual cost of goods tend to be less expensive Additionally, high market demand or growth in market trends and demand (higher past sales and current sales) motivated managers to buy more goods thereby increasing profits margins. However, underinvestment in working capital tend be highly influenced by high anchoring bias (higher initial pricelist offers), decline in market trends or demand (e.g. low past sales and current demand) discouraged managers to minimums level of working capital in inventory leading to decreased in profit margins "all things equal being equal. We noted that participants have either overinvested or underinvested before. In particular, participants 12,10 and 5 replied as follows:

"I would like to invest more in working capital in inventory whenever the initial price of good is low. The market value of the goods would not too expensive and this would boost my profit margins. Similarly, I will also increase inventory when past and current sales increases. This will enable me meet growing customers' demands and thus increase my profits. But, I will certainly invest less in working capital inventory whenever the initial price is expensive because I cannot afford that much. At the same I will buy less goods due low previous sales and current demand because most time it 
INTERNATIONAL JOURNAL OF ACADEMIC RESEARCH IN BUSINESS AND SOCIAL SCIENCES Vol. 10, No. 5, May, 2020, E-ISSN: 2222-6990 @ 2020 HRMARS

took a long period of time to sell goods which affected my expected returns(participant,12). In addition, participants 10 stated that :........."I buy more goods when the initial price and price quotation is low because the actual cost would be less expensive which facilitates sales revenue and to meet expected profits. Nonetheless, I like to purchase few quantity of goods when the high initial prices that reduced sales returns". Moreover, I will also buy more goods due high past sales and current sales to satisfy market demand to boost my profits. Nonetheless, I will decrease the quantity of goods due to high initial prices and low previous and current sales are low"

This finding may suggest managers who perform better tend to rely on low initial prices offer and higher past and current sales to meet customer needs all things else being equal.

Additionally, anchoring on customer's trust working capital management tend to increases or decreases working capital in accounts receivables which also increases or decreases firm performance. For instance, overinvestment in working capital in accounts receivable occurred when managers have high level of trust for customers, based on their long-term business relationship, they tend to grant more credit to customers. However, they tend to reduce trade credit to customers with short-term business relationship due low level of trust, resulting in underinvestment in accounts receivable. This decision reflects manager's belief that customers with long term business relationship tend to have higher ability to pay credit or lower default rate and result in higher sales revenue and increase profits margins than customers with short term business relationship. These views were obtained from participants 3 stated that:

"I consider trust as key factor in granting credit to customers whom I have good business relationship with. This normally gives me some rough idea about their payment because they have been buying from me". So I give more credit to customers that I trust them a lot. But I offer less credit to customers with short-term business relationship because I don't know them too well. I think that granting more credit to most trust customers in most cases boost my sales and profits margins than the less trusted customers. I won't offer more credit to customers with short-term business even if the paid early. I need to study them for some time in order to build strong level of trust. Moreover, Participants 4 view trust as the most important factor in business and said that: "I will sell to regular customers on credit, especially those who have been buying from me over a period of time, since this will help me know if they can pay or not". "I grant more credit to old customer based on extent of level trust due to number of years of business relationship. I granted less credits to other customers because the trust is not too strong due short business relationship. Of course, these practices have improved my turnover and profits, especially among long term customers. Well, if the less trusted customers make early, I may grant them more credit depending on many relationship and the timing.

The implication of this finding show highly trusted customers have low default risk which can enhance revenue generation and boost firm performance.

\section{Discussion and Conclusion}

This study explores anchoring bias in working capital management and performance of SMEs. We found that SME managers were prone to anchoring bias rely on self-generated and provided 
anchors which consistent with empirical evidence (Khan et al. 2017). Furthermore, Baker et al. (2012) and theoretical evidence (Tversky and Kahneman, 1974). The use of initial price offers (pricelist and price quotation) and market trends allow managers(owners) to increase or decrease working capital in inventory. While anchoring customer trust enables managers to increase or decrease accounts receivable via trade credit which contributes to increases and decreases profit margins. The findings mean that efficient manager tend to favor lower provided anchor and high self-generated anchors.

The results show that it not enough to study working capital without considering anchoring bias. This study makes several contributions. Our article is the first to explore anchoring bias in working capital management and thus we provide fresh evidence and extend literature in anchoring bias. Furthermore, we make new contributions to body on knowledge based on the evidence of influence of anchoring bias on working capital management and performance. We then propose that:(1) higher anchoring bias leads to decrease in working capital in inventory and performance and increase working capital in accounts receivable and performance (2) Lower anchoring bias leads to an increase in working capital investment inventory and performance and decrease working capital in accounts receivable and performance.

This shows that application of anchoring and adjustment bias in working capital and performance is relevant to SMEs that might want to maximise working capital when face with uncertainty, especially Ghanaian SMEs managers who are convinced that the proper use of anchoring and adjustment can better improve working capital management and performance rather than relying on working capital models. This finding helps policy makers and regulators of SMEs in Ghana and elsewhere to fashion out necessary policies and programs to enhance SMEs financial management and practices. Financial institution, banks, Microfinance institutions and other lending institutions can incorporate anchoring behavioral factors into credit assessment for SMEs loans by simplifying computation of interest on loan and amortisation of loan to facilitate informed decision by these managers. Second, it provides knowledge to managers how their behaviors can negatively or positively impact working capital decision and performance. This knowledge helps managers to negotiate for favorable suppliers and buyers by identifying key initial relevant information inventory decision and credit assessment. Finally, we fail to general our results so future researcher need to examine effects of SMEs Managers anchoring bias on working capital management and performance.

\section{References}

Ahmad, K., \& Zabri, S. M. (2016). Inventory management practices among Malaysian micro retailing enterprises. Journal of Business and Retail Management Research, 11(1),103-115.

Al-Madhoun, M., and Analoui, F. (2003), "Management and development: the training programs for small and micro enterprises in Palestinian territories", Management Research News, 26 (6), 39-67.

Akoena, S., \& Gockel, F. A. (2002). Financial intermediation for the poor: credit demand by micro, small and medium enterprises in Ghana: A further assignment for financial sector policy. IFLIP research paper, 6.

Baker, M., Pan, X., \& Wurgler, J. (2012). The effect of reference point prices on mergers and acquisitions. Journal of Financial Economics, 106(1), 49-71.

Bandara, R. M. S., \& Rathnasiri, U. A. H. A. (2016). The Working Capital Management Practices of Small and Medium Enterprises (SMEs) in Sri Lanka, ICME 2016, Faculty of Management and Finance, University of Ruhuna. 
INTERNATIONAL JOURNAL OF ACADEMIC RESEARCH IN BUSINESS AND SOCIAL SCIENCES

Vol. 10, No. 5, May, 2020, E-ISSN: 2222-6990 @ 2020 HRMARS

Bernard, H. R. (2002). Research Methods in Anthropology: Qualitative and quantitative methods. ( $3^{\text {rd }}$ edn). Walnut Creek, California: Altamira Press.

Birkinshaw, J., Brannen, M. Y., \& Tung, R. L. (2011). From a distance and generalizable to up close and grounded: Reclaiming a place for qualitative methods in international business research. Journal of International Business Studies, 42(5),573-581.

Burke, L. A., \& Miller, M. K. (2001). Phone interviewing as a means of data collection: Lessons learned and practical recommendations. In Forum Qualitative Sozialforschung/Forum: Qualitative Social Research, 2(2), Art. 7.

Campbell, S. D., \& Sharpe, S. A. (2009). Anchoring bias in consensus forecasts and its effect on market prices. Journal of Financial and Quantitative Analysis, 44(2), 369-390.

Cachia, M., \& Millward, L. (2011). The telephone medium and semi-structured interviews: A complementary fit. Qualitative Research in Organizations and Management: An International Journal. 6. 265-277.

Cen, L., Hilary, G., \& Wei, K. J. (2013). The role of anchoring bias in the equity market: Evidence from analysts' earnings forecasts and stock returns. Journal of Financial and Quantitative Analysis, 48(1), 47-76.

Creswell, J. W., \& David, J. C. (2018). Research Design: Qualitative, Quantitative, and Mixed Methods Approaches. (5th edn.). Los Angeles: SAGE. Publication.

Deakin, H., \& Wakefield, K. (2014). Skype interviewing: Reflections of two PhD researchers. Qualitative research, 14(5), 603-616.

Domegan, C., \& Fleming, D. (2007). Marketing research in Ireland: Theory and practice. Third edition: Dublin: Gill and Macmillan.

Donkor, J. (2015). Working Capital Management of SMEs: Ghana's version of the story. Journal of Economics, Management and Trade,10(3) 1-12.

Duclos, R. (2015). The psychology of investment behavior:(De) biasing financial decision-making one graph at a time. Journal of Consumer psychology, 25(2), 317-325.

Dyer, Jr. W. G., \& Wilkins, A. L. (1991). Better stories, not better constructs, to generate better theory: A rejoinder to Eisenhardt. Academy of management review, 16(3), 613-619.

Epley, N., \& Gilovich, T. (2006). The anchoring-and-adjustment heuristic: Why the adjustments are insufficient. Psychological science, 17(4), 311-318.

Englich, B., Mussweiler, T., \& Strack, F. (2006). Playing dice with criminal sentences: The influence of irrelevant anchors on experts' judicial decision making. Personality and Social Psychology Bulletin, 32(2), 188-200.

Etikan, I., Musa, S. A., \& Alkassim, R. S. (2016). Comparison of convenience sampling and purposive sampling. American journal of theoretical and applied statistics, 5(1), 1-4.

Fenig, S., Levav, I., Kohn, R., \& Yelin, N. (1993). Telephone vs face-to-face interviewing in a community psychiatric survey. American Journal of Public Health, 83(6), 896-898.

Filbeck, G., \& Lee, S. (2000). Financial management techniques in family businesses. Family Business Review, 13(3), 201-216.

Fontana, A., \& Frey, J. H. (2000). The interview: From structured questions to negotiated text. Handbook of qualitative research, 2(6), 645-672.

George, T. J., and Hwang, C. Y. (2004). The 52-week high and momentum investing. The Journal of Finance, 59,2145-76. Analysts Journal, 60(4), 35-43. 
INTERNATIONAL JOURNAL OF ACADEMIC RESEARCH IN BUSINESS AND SOCIAL SCIENCES

Vol. 10, No. 5, May, 2020, E-ISSN: 2222-6990 @ 2020 HRMARS

Degeorge, F., Patel, J., \& Zeckhauser, R. (1999). Earnings management to exceed thresholds. Journal of Business, 72(1), 1-33.

Glogowska, M., Young, P., \& Lockyer, L. (2011). Propriety, process and purpose: Considerations of the use of the telephone interview method in an educational research study. Higher Education, 62(1)17-26.

Hamza, K., Mutala, Z., \& Antwi, S. K. (2015). Cash management practices and financial performance of small and medium enterprises (SMEs) in the northern region of Ghana. International Journal of Economics, Commerce and Management, 3(7), 456-480.

Hirshleifer, D. (2001). Investor psychology and asset pricing. The Journal of Finance, 56(4), 15331597.

Hogarth, R. M. (1981), Beyond discrete bias functional and dysfunctional aspects of judgment heuristics, psychological bulletin 197.

Jones, P., Hillier, D. Turner, D., and Comfort, D. (2004). "Betting on the Exchanges: Changing Customer Relationships in the Sports Betting Market in the UK." Management Research News 27: 95103.

Khan, H. H., Naz, I., Qureshi, F., \& Ghafoor, A. (2017). Heuristics and stock buying decision: Evidence from Malaysian and Pakistani stock markets. Borsa Istanbul Review, 17(2),97-110.

Johnson, J. E., \& Bruce, A. C. (2001). Calibration of subjective probability judgments in a naturalistic setting. Organizational Behavior and Human Decision Processes, 85(2), 265-290.

Jetter, M., \& Walker, J. K. (2016). Anchoring in financial decision-making: Evidence from Jeopardy! Journal of Economic Behavior \& Organization. 141. 164-176.

Latham, G. P., Budworth, M. H., Yanar, B., \& Whyte, G. (2008). The influence of a manager's own performance appraisal on the evaluation of others. International Journal of Selection and Assessment, 16(3), 220-228.

Liao, L- C., Chou, Y. R., \& Chiu, B. (2013). Anchoring Effect on Foreign Institutional Investors" Momentum Trading Behavior: Evidence from Taiwan Stock Market. North American Journal of Economics and Finance, 26, 72-91.

Maharani, S., \& Witiastuti, R. S. (2015). Fenomena Market Overreaction di Bursa Efek Indonesia. Management Analysis Journal, 1(2), 120- 128.

Marsidi, A. (2019). Sustainable supply chain management of Malaysian small business: Accounting perspective. International Journal of Supply Chain Management, 8(4), 596-600.

Merriam, S. B. (2009). Qualitative case study research. Qualitative research: A guide to design and implementation, 39-54.

Mussweiler, T., \& Schneller, K. (2003). What Goes Up Must Come Down-How Charts Influence Decisions to Buy and Sell Stocks. The Journal of Behavioral Finance, 4(3),121-130

Northcraft, G. B., \& Neale, M. A. (1987). Experts, amateurs, and real estate: An anchoring-andadjustment perspective on property pricing decisions. Organizational behavior and human decision processes, 39(1), 84-97.

Pansiri, J., \& Temtime, Z. T. (2008), “Assessing managerial skills in SMEs for capacity building”, Journal of Management Development, 27(2),251-60.

Park, C. (2010). When does the dividend-price ratio predict stock returns? Journal of Empirical Finance, 17(1), 81-101.

Pompian, M. M. (2012). Behavioral finance and investor types: managing behavior to make better investment decisions. ( $2^{\text {nd }}$ edn.) John Wiley \& Sons. 
INTERNATIONAL JOURNAL OF ACADEMIC RESEARCH IN BUSINESS AND SOCIAL SCIENCES

Vol. 10, No. 5, May, 2020, E-ISSN: 2222-6990 ㄷ 2020 HRMARS

Ritov, I. (1996). Anchoring in simulated competitive market negotiation. Organizational Behavior and Human Decision Processes, 67(1), 16-25.

Shelden, D. L., Angell, M. E., Stoner, J. B., \& Roseland, B. D. (2010). School principals' influence on trust: Perspectives of mothers of children with disabilities. The Journal of Educational Research, 103(3), 159-170.

Siggelkow, N. (2007). Persuasion with case studies. Academy of management journal, 50(1), 20-24.

Spradley, J. (1979). Asking descriptive questions. The ethnographic interview, 1, 44-61.

Stake, R. (2000). Case studies. In N. K. Denzin \& Y. S. Lincoln (Eds.), Handbook of qualitative research (pp. 435-454). Thousand Oaks, CA: Sage.

Strack, F., \& Mussweiler, T. (1997) 'Explaining the enigmatic anchoring effect: Mechanisms of selective accessibility' Journal of Personality and Social Psychology, 73()437 - 446.

Strauss, A., \& Corbin, J. (1998). Basics of qualitative Research: Techniques and procedures for Developing Grounded theory. Thousand Oaks, CA: Sage.

Trier-Bieniek, A. (2012). Framing the telephone interview as a participant-centered tool for qualitative research: a methodological discussion. Qualitative Research, 12(6), 630-644.

Tversky, A., \& Kahneman, D. (1974). Judgment under uncertainty: Heuristics and biases, Science, 185(4157), 1124-1131.

Vogl, S. (2013). Telephone versus face-to-face interviews: Mode effect on semi structured interviews with children. Sociological Methodology, 43(1), 133-177.

Yin, R. K. (2003). Case Study Research: Design and Methods. ( $3^{\text {rd }}$ edn). Sage Publications, London.

Yin, R. K. (1994). Case Study Research: Design and Methods. second edition. SAGE Publications, London. 